CLINICAL STUDY

\title{
Metabolic parameters and adipokine profile during GH replacement therapy in children with GH deficiency
}

\author{
A Ciresi, M C Amato, A Criscimanna, A Mattina, C Vetro, A Galluzzo, G D’Acquisto and C Giordano \\ U.O. per la Diagnosi e Cura delle Endocrinopatie Autoimmuni e del Diabete di Tipo uno, Sezione di Endocrinologia, Dipartimento di Oncologia Sperimentale e \\ Applicazioni Cliniche (DOSAC), Facoltà di Medicina e Chirurgia, Università degli Studi di Palermo, Palermo, Italy \\ (Correspondence should be addressed to C Giordano who is now at Endocrinology, DOSAC Faculty of Medicine Università degli Studi, Palermo 90127, \\ Italy; Email: cgiordan@unipa.it)
}

\begin{abstract}
Objective: GH replacement therapy in children with GH deficiency (GHD) mainly promotes linear growth. Not only have very few studies fully analyzed the metabolic consequences of GH therapy, but also the question as to whether GH may affect adipokine secretion has been insufficiently investigated. Our aim was to study the effects of GH replacement therapy on auxological data, lipid and glycemic profiles, insulin homeostasis (HOMA-IR) and serum adipokines in children.

Methods: This was a 1-year prospective study. Thirty-four GHD children $(11.6 \pm 2.6$ years) and thirty healthy matched controls were enrolled. Children affected by GHD were studied both before beginning continuous GH replacement therapy and again at 12 months.

Results: At the beginning of the study, total and LDL cholesterol were higher in GHD children than in controls $(P<0.001)$, whereas HDL cholesterol, triglycerides, insulin, HOMA-IR, leptin, and adiponectin were similar. At 12 months of continuous GH replacement therapy in the GHD group, there was a significant increase in both auxological data and IGF-I $(P<0.001)$; total cholesterol $(P<0.001)$, LDL $(P<0.001)$, triglycerides $(P<0.005)$, and leptin $(P<0.001)$ decreased significantly; HDL $(P<0.003)$, insulin $(P<0.001)$, HOMA-IR $(P<0.001)$ increased while adiponectin was unmodified. Furthermore, IGF-I $\Delta$ showed an inverse correlation with leptin $\Delta(\rho=-0.398, P=0.02)$. Conclusions: In GHD children, the evaluation of metabolic parameters proves to be a useful tool for the evaluation of auxological parameters during GH replacement therapy. In our study, GH replacement therapy in GHD children improved final height, restored IGF-I levels, reduced leptin levels, and improved the lipid profile, without producing any unfavorable effects on glucose metabolism.
\end{abstract}

European Journal of Endocrinology 156 353-360

\section{Introduction}

The main role of growth hormone $(\mathrm{GH})$ replacement therapy in children with GH deficiency (GHD) is to promote linear growth (1). Nevertheless, it is well known that $\mathrm{GH}$ brings about a large number of metabolic effects, involving lipid and glucose homeostasis, lean and fat mass (2-5). In adults, GHD influences body composition, decreases bone mineral density, muscle strength and cardiac morphology and performance, accelerates atherosclerosis, promotes an unfavorable lipid and glucose profile, peripheral insulin resistance, all of which may lead to higher cardiovascular morbidity and a poor quality of life (6). It is widely accepted that $\mathrm{GH}$ treatment in adults produces beneficial metabolic effects $(7,8)$, while apart from reporting auxological data, in pediatric patients, only a few studies have fully analyzed the metabolic consequences of GH replacement therapy. Moreover, the question as to whether GH may affect adipokine secretion in children has been insufficiently investigated: leptin and adiponectin are hormones that are only synthesized and secreted by adipocytes (9); they are strictly linked to insulin sensitivity status and their levels depend on body composition $(10,11)$.

It has been suggested that in children (12), as in adults (13), GH treatment might bring about a reduction in leptin probably in relation to fat mass reduction. In young obese patients affected by the Prader-Willi Syndrome, it has been established that GH therapy decreases body mass and leptin concentration while insulin sensitivity indexes are not significantly influenced (14). It should be borne in mind that still not enough is known about the complex interplay between adipokines and $\mathrm{GH}$ and the possible early development of alterations in insulin sensitivity in GHD children. The aim of this study was to investigate lipid and glucose profile, insulin homeostasis, adipokine serum levels in prepubertal GHD children at baseline and after 12 months of GH replacement therapy and in age, sex-pubertal status, body mass index (BMI)matched controls. 


\section{Subjects and methods}

\section{Patients}

Thirty-four prepubertal children, 25 boys and 9 girls, aged $11.6 \pm 2.6$ years (range 6.1-15.3 years), affected by idiopathic isolated GHD and meeting the clinical and auxological criteria of the GH Research Society (15), were enrolled in the study. Informed consent was obtained from parents. GHD was assessed by insulinlike growth factor-I (IGF-I) levels below the normal range and low-peak $\mathrm{GH}$ response in two dynamic $\mathrm{GH}$ tests $(<20 \mu \mathrm{g} / \mathrm{l}$ during GHRH + ARG test and $<10 \mu \mathrm{g} / \mathrm{l}$ during insulin tolerance test). We excluded children with multiple pituitary hormone deficiency in order to avoid other possible influences on glucose and lipid metabolism. The patients enrolled had never received any kind of hormonal replacement therapy or drug.

\section{Control group}

Thirty healthy subjects, 24 boys and 6 girls, matched for age, sex-pubertal status, BMI, nutritional behavior, and geographical area, aged $12.3 \pm 2.1$ (range 7.9-14.0 years), were recruited as control group. Informed consent was obtained from parents. GHD was excluded by normal age-corrected levels of IGF-I. Their growth velocity and metabolic parameters were studied both at the beginning of the continuous therapy and then again at 12 months.

\section{Study design}

At the beginning of the study, all subjects were investigated for auxological data (height SDS, weight SDS, BMI, bone age, chronological/bone age ratio), serum total IGF-I levels, lipid profile (total cholesterol, HDL, LDL, triglycerides), glucose metabolism (fasting glucose and insulin levels), aspartate aminotransferase (AST), alanine aminotransferase (ALT), leptin, and adiponectin levels. Insulin resistance was evaluated by the homeostasis model assessment insulin resistance index (HOMA-IR), applying the Matthews formula (fasting serum insulin $(\mu \mathrm{U} / \mathrm{ml}) \times$ fasting plasma glucose $(\mathrm{mmol} / \mathrm{l}) / 22.5)$ (16). GHD children received biosynthetic GH (recombinant human GH) once daily at bedtime with a pen injection system; the initial GH dose was $25 \mathrm{mcg} / \mathrm{kg}$ per day s.c.; during the study, in order to maintain serum IGF-I levels within the normal range for sex and chronological age, the cumulative $\mathrm{GH}$ dose administered to all patients was $25 \mathrm{mcg} / \mathrm{kg}$ per day for the first 6 months, $30 \mathrm{mcg} / \mathrm{kg}$ per day from months 6 to 9 , and finally $35 \mathrm{mcg} / \mathrm{kg}$ per day for the last 3 months. Blood samples for metabolic parameters were taken at the start of the study and after 12 months both from GH-treated and healthy children; after centrifugation, all samples were frozen $\left(-20{ }^{\circ} \mathrm{C}\right)$ until assayed.

\section{Anthropometric measurements}

Height and weight were expressed in SDS; bone age delay was evaluated according to Tanner and Whitehouse (TW2) method (17).

\section{Hormone and biochemical assays}

Glycemic, AST, ALT and lipid (HDL and total cholesterol, triglycerides, LDL) levels were measured in our centralized laboratory with standard methods. Serum GH was assessed by ELISA method (BioSource hGH-EASIA kit, Nivelles, Belgium). The sensitivity of the method was $0.07 \mu \mathrm{g} / \mathrm{l}$. The inter- and intra-assay coefficients of variation (CV values) were 3.6-4.4 and 3.7-9.8\% respectively, at GH levels of $6.4-21.2$ and $1.9-13.1 \mu \mathrm{g} / \mathrm{l}$ respectively. Serum total IGF-I was assayed in the same laboratory by ELISA method (OCTEIA IGF-I kit, IDS Inc., Fountain Hills, AZ, USA). The sensitivity of the method was $1.9 \mu \mathrm{g} / \mathrm{l}$. The inter- and intra-assay $\mathrm{CV}$ values were $7-7.1$ and $2.3-3.5 \%$ respectively, at IGF-I levels of 90.7186 and $66.7-120.9 \mu \mathrm{g} / \mathrm{l}$ respectively. The normal ranges (males and females combined) of total IGF-I levels $(\mu \mathrm{g} / \mathrm{l})$ were: $12-108$ (0-1 years); 13-100 (1-3 years); 26-280 (3-6 years); 85-230 (6-9 years); 98-404 (9-12 years); 142-525 (12-15 years); 146-415 (15-20 years). Serum leptin levels were measured by ELISA according to the manufacturer's instructions (Linco Research, Inc., St Charles, MO, USA). The sensitivity limit of the assay was $0.5 \mathrm{ng} / \mathrm{ml}$, and the intra- and inter-assay $\mathrm{CV}$ values were $2.6-4.6$ and $2.6-6.2 \%$ respectively, at leptin levels of 2.34-28.9 ng/ml. Serum adiponectin levels were measured by ELISA according to the manufacturer's instructions (Linco Research, Inc.). The sensitivity limit of the assay was $0.78 \mathrm{ng} / \mathrm{ml}$, and the intra- and inter-assay CV values were 7.4 and $2.4-8.4 \%$ respectively, at adiponectin levels of $17.73-39.10 \mathrm{ng} / \mathrm{ml}$. Serum insulin was measured by ELISA (Mercodia Insulin ELISA, Arnika, Milan, Italy).The sensitivity of the method was $1 \mu \mathrm{UI} / \mathrm{ml}$.

\section{Statistical analysis}

We used the SPSS 13 software, Windows Edition, for all our statistical analyses. Continuous variables were analyzed as mean values \pm s.D. Rates and proportions were calculated for categorical data. Differences between GHD and controls were analyzed by MannWhitney U-test (non-parametric test), as they were continuous variables without normal distribution. The differences between paired continuous variables in the GHD group (before and 1 year after therapy) were analyzed by the Wilcoxon test. Correlations among continuous variables without normal distribution were determined by using the Spearman's test (non-parametric equivalent for Pearson test). For categorical variables, differences were analyzed by means of the $\chi^{2}$-test and Fisher's exact test when appropriate. $P<0.05$ was considered statistically significant. 


\section{Results}

Auxological and metabolic parameters are shown in Table 1 at baseline (cases and controls) and in Table 2 at 12 months of continuous therapy (only GHD cases). The patients recruited in our study were all prepubertal and maintained this status during the first observation period, i.e., during the first 12 months of GH therapy (Table 3). Controls did not show any significant differences in metabolic data and IGF-I levels with respect to baseline (fasting glycemia: $88.6 \pm 5.9$ vs $85.3 \pm 7.1 \mathrm{mg} / \mathrm{dl}$, $P=0.055$; total cholesterol: $120.5 \pm 14.5$ vs $127.2 \pm$ $16.3 \mathrm{mg} / \mathrm{dl}, P=0.098$; HDL cholesterol: $50.4 \pm 11.4 \mathrm{vs}$ $49.2 \pm 10.1 \mathrm{mg} / \mathrm{dl}, P=0.668$; LDL cholesterol: $52.2 \pm$ 19.7 vs $54.3 \pm 17.8 \mathrm{mg} / \mathrm{dl}, P=0.668$; triglycerides: $89.3 \pm 23.8$ vs $90.3 \pm 21.8 \mathrm{mg} / \mathrm{dl}, P=0.869$; insulin levels: $10.7 \pm 11$ vs $11.3 \pm 15.7 \mu \mathrm{U} / \mathrm{ml}, P=0.873$; HOMA-IR: $2.34 \pm 2.39$ vs $2.39 \pm 2.41, P=0.936$; leptin levels: $5.14 \pm 5.03$ vs $6.02 \pm 5.01 \mathrm{ng} / \mathrm{ml}, P=0.499$; adiponectin levels: $14.5 \pm 8.2$ vs $14.3 \pm 7.2 \mathrm{ng} / \mathrm{ml}$, $P=0.960$ ). Auxological parameters (height and weight SDS) in the control group increased during the first 12 months of the observation period in comparison with basal evaluation (height SDS: $-1.52 \pm 0.60$ vs $-0.91 \pm 0.39, P<0.001$; weight SDS: $-0.98 \pm 0.60$ vs $-0.49 \pm 0.53, P=0.001$ ), while there was no significant increase in IGF-I levels $(281.3 \pm 132.7$ vs $331.6 \pm$ $123.2 \mu \mathrm{g} / \mathrm{l}, P=0.134)$.
At baseline

Auxological data and IGF-I levels. As expected, at the beginning of the study, height SDS $(P=0.044)$, bone age $(P=0.007)$, and serum IGF-I levels $(P<0.001)$ were significantly lower in GHD children than in controls; conversely, chronological/bone age ratio was significantly higher $(P<0.001)$. No significant difference was found in BMI (Table 1).

Metabolic data. Significant differences between GHD children and controls were observed in lipid profiles, with total cholesterol $(163.08 \pm 32.67$ vs $120.50 \pm$ 14.53; $P<0.001)$ and LDL cholesterol $(95.15 \pm 34.32$ vs $52.22 \pm 19.78$; $P<0.001$ ) higher in the GHD group than in controls, although within the normal range. No differences were found in glycemia $(P=0.206)$, insulinemia $(P=0.553)$, HOMA-IR $(P=0.553)$, HDL cholesterol $(P=0.339)$, triglycerides $(P=0.710)$, AST $(P=0.967)$, ALT $(P=0.815)$, leptin $(P=0.989)$, and adiponectin $(P=0.880)$.

\section{At 12 months of GH therapy}

Auxological data and IGF-I levels. In the GHD group, serum IGF-I levels $(P<0.001)$, height SDS $(P<0.001)$,

Table 1 Auxological and metabolic data at diagnosis.

\begin{tabular}{|c|c|c|c|}
\hline & Group A (GHD) $n=34$ & Group B (control) $n=\mathbf{3 0}$ & \\
\hline & & & $P^{a}$ \\
\hline Males: no. (\%) & 25 (73.52) & $24(80)$ & 0.753 \\
\hline Females: no. (\%) & $9(26.47)$ & $6(20)$ & \\
\hline Auxological data & Mean \pm S.D. & Mean \pm S.D. & $P^{b}$ \\
\hline Chronological age & $11.60 \pm 2.63$ & $12.32 \pm 2.15$ & 0.604 \\
\hline Height SDS & $-2.03 \pm 0.64$ & $-1.52 \pm 0.60$ & $0.044^{*}$ \\
\hline Weight SDS & $-1.28 \pm 1.08$ & $-0.98 \pm 0.60$ & 0.312 \\
\hline BMI & $17.92 \pm 3.90$ & $18 \pm 2.38$ & 0.730 \\
\hline Bone age & $9.84 \pm 2.70$ & $12.24 \pm 2.22$ & $0.007^{\star}$ \\
\hline Chronological/bone age ratio & $1.21 \pm 0.18$ & $1 \pm 0.03$ & $<0.001^{\star}$ \\
\hline Familiar height target $(\mathrm{cm})$ & $166.51 \pm 7.71$ & $168.95 \pm 4.63$ & 0.534 \\
\hline IGF-I $(\mu \mathrm{g} / \mathrm{I})$ & $79.63 \pm 35.51$ & $281.36 \pm 132.72$ & $<0.001^{*}$ \\
\hline \multicolumn{4}{|l|}{ Metabolic data } \\
\hline Fasting glycemia (mg/dl) & $84.23 \pm 10.52$ & $88.60 \pm 5.91$ & 0.206 \\
\hline Total cholesterol (mg/dl) & $163.08 \pm 32.67$ & $120.50 \pm 14.53$ & $<0.001^{*}$ \\
\hline HDL cholesterol (mg/dl) & $47.08 \pm 13.63$ & $50.40 \pm 11.45$ & 0.339 \\
\hline LDL cholesterol (mg/dl) & $96.15 \pm 34.32$ & $52.22 \pm 19.78$ & $<0.001^{*}$ \\
\hline Triglycerides $(\mathrm{mg} / \mathrm{dl})$ & $99.20 \pm 45.04$ & $89.33 \pm 23.81$ & 0.710 \\
\hline ALT $(U \mathrm{I} / \mathrm{l})$ & $22.47 \pm 5.98$ & $22.20 \pm 8.12$ & 0.815 \\
\hline AST (UI/I) & $16.17 \pm 6.41$ & $15.40 \pm 2.01$ & 0.967 \\
\hline Insulin levels $(\mu \mathrm{U} / \mathrm{ml})$ & $7.50 \pm 5.77$ & $10.76 \pm 11$ & 0.553 \\
\hline Homa-IR & $1.58 \pm 1.26$ & $2.34 \pm 2.39$ & 0.553 \\
\hline Leptin levels (ng/ml) & $6.22 \pm 8$ & $5.14 \pm 5.03$ & 0.989 \\
\hline Adiponectin levels (ng/ml) & $14.43 \pm 7.27$ & $14.49 \pm 8.23$ & 0.880 \\
\hline
\end{tabular}

*Significant values when $P<0.05$.

apearson $\chi^{2}$.

${ }^{\mathrm{b}}$ Mann-Whitney test. 
Table 2 Auxological and metabolic data after 12 months of growth hormone (GH) replacement therapy.

\begin{tabular}{|c|c|c|c|}
\hline & GHD $n=34$ (at diagnosis) & GHD $n=\mathbf{3 4}$ (at 12 months) & \\
\hline & $M e a n \pm S . D$. & 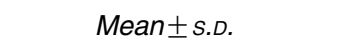 & $P^{\mathrm{a}}$ \\
\hline Height SDS & $-2.03 \pm 0.64$ & $-1.62 \pm 0.58$ & $<0.001^{*}$ \\
\hline Weight SDS & $-1.28 \pm 1.08$ & $-0.97 \pm 1.02$ & $<0.001^{*}$ \\
\hline BMI & $17.92 \pm 3.9$ & $18.59 \pm 4.05$ & $0.001^{*}$ \\
\hline Bone age & $9.84 \pm 2.70$ & $11.27 \pm 2.60$ & $<0.001^{*}$ \\
\hline Chronological/bone age ratio & $1.21 \pm 0.18$ & $1.12 \pm 0.08$ & $<0.001^{*}$ \\
\hline IGF-I $(\mu \mathrm{g} / \mathrm{l})$ & $79.63 \pm 35.51$ & $353.85 \pm 152.62$ & $<0.001^{*}$ \\
\hline Fasting glycemia (mg/dl) & $84.23 \pm 10.52$ & $86.94 \pm 6.18$ & 0.188 \\
\hline Total cholesterol (mg/dl) & $163.08 \pm 32.67$ & $155.20 \pm 34.86$ & $<0.001^{*}$ \\
\hline HDL cholesterol (mg/dl) & $47.08 \pm 13.63$ & $52.73 \pm 12.45$ & $0.003^{*}$ \\
\hline LDL cholesterol (mg/dl) & $96.15 \pm 34.32$ & $84.30 \pm 34.61$ & $0.001^{*}$ \\
\hline Triglycerides (mg/dl) & $99.20 \pm 45.04$ & $90.82 \pm 41.18$ & $0.005^{*}$ \\
\hline $\operatorname{ALT}(\mathrm{UI} / \mathrm{I})$ & $22.47 \pm 5.98$ & $23.61 \pm 8.29$ & 0.639 \\
\hline AST $(U \mathrm{II} / \mathrm{l})$ & $16.17 \pm 6.41$ & $15.61 \pm 4.48$ & 0.708 \\
\hline Insulin levels $(\mu \mathrm{U} / \mathrm{ml})$ & $7.50 \pm 5.77$ & $17.47 \pm 11.29$ & $<0.001^{*}$ \\
\hline Homa-IR & $1.58 \pm 1.26$ & $3.73 \pm 2.39$ & $<0.001^{*}$ \\
\hline Leptin levels (ng/ml) & $6.22 \pm 8$ & $3.47 \pm 5.91$ & $<0.001^{*}$ \\
\hline Adiponectin levels (ng/ml) & $14.43 \pm 7.27$ & $14.98 \pm 6.02$ & 0.509 \\
\hline
\end{tabular}

*Significant values when $P<0.05$

aWilcoxon test.

and BMI $(P=0.001)$ increased significantly after 12 months of GH therapy with respect to baseline values, while chronological/bone age ratio $(P<0.001)$ and weight $(P<0.001)$ decreased (Table 2$)$.

Metabolic data. Total cholesterol $(163.08 \pm 32.67$ vs $155.20 \pm 34.86 ; P<0.001)$, LDL $(95.15 \pm 34.32$ vs $84.30 \pm 34.61 ; P=0.001)$, and triglycerides $(99.20 \pm$ 45.04 vs $90.82 \pm 41.18, P=0.005)$ showed a significative reduction after the first 12 months of therapy, while a highly significant increase in HDL cholesterol was observed $(47.08 \pm 13.63$ vs $52.73 \pm 12.45$, $P=0.003$; Fig. 1). AST $(16.17 \pm 6.41$ vs $15.61 \pm$ $4.48, P=0.708)$ and ALT $(22.47 \pm 5.98$ vs $23.61 \pm$ $8.29, P=0.639)$ after 12 months were similar to baseline. Insulinemia $(7.50 \pm 5.77$ vs $17.47 \pm 11.29)$ and HOMA-IR $(1.58 \pm 1.26$ vs $3.73 \pm 2.39)$ increased when compared with baseline values $(P<0.001)$, while glycemia was unmodified $(84.23 \pm 10.52$ vs $86.94 \pm$ $6.18, P=0.188)$. Leptin values significantly decreased $(6.22 \pm 8$ vs $3.47 \pm 5.91, P<0.001)$ after replacement therapy, while adiponectin $(14.43 \pm 7.27$ vs $14.98 \pm$ $6.02, P=0.509)$ remained unmodified in all $\mathrm{GH}$-treated children (Fig. 2). Considering IGF-I as the main marker of successful therapy, we examined the possible correlations between IGF-I and all metabolic parameters both at baseline and after 12 months of GH therapy. In addition, we calculated $\Delta$ values ( $0-12$ months) of total, HDL and LDL cholesterol, triglycerides, insulinemia, HOMA-IR, leptin, and adiponectin and analyzed their correlation with IGF-I $\Delta$, resulting in a significant inverse correlation between leptin $\Delta$ and IGF-I $\Delta$ $(\rho=-0.398 ; P=0.02$; Fig. 3).

\section{Discussion}

In the present study, baseline leptin and adiponectin concentrations were identical in GHD and healthy children. A significant decrease in leptin levels was found at 1 year of continuous GH treatment without any change in adiponectin. Insulin sensitivity was only slightly influenced by GH therapy with an increase in HOMA-IR, related to increased insulin levels without

Table 3 Pubertal status (Tanner) at baseline and after 12 months of growth hormone $(\mathrm{GH})$ replacement therapy.

\begin{tabular}{|c|c|c|c|}
\hline & $\begin{array}{c}\text { GHD } n=34 \\
\text { (at diagnosis) }\end{array}$ & $\begin{array}{c}\text { GHD } \boldsymbol{n}=\mathbf{3 4} \\
\text { (at } 12 \text { months) }\end{array}$ & \\
\hline & No. (\%) & No. (\%) & $P$ \\
\hline $\mathrm{PH}$ status & & & $<0.001^{\star}$ \\
\hline $\mathrm{PH} 1$ & $34(100)$ & $20(58.8)$ & \\
\hline $\mathrm{PH} 2$ & - & $14(41.2)$ & \\
\hline $\mathrm{PH} 3$ & - & - & \\
\hline $\mathrm{PH} 4$ & - & - & \\
\hline G status (No. 25 boys) & & & $0.014^{*}$ \\
\hline G1 & $25(100)$ & $19(76)$ & \\
\hline G2 & - & $6(24)$ & \\
\hline G3 & - & - & \\
\hline G4 & - & - & \\
\hline B status (No. 9 girls) & & & 0.157 \\
\hline B1 & $9(100)$ & $7(77.8)$ & \\
\hline B2 & - & $2(22.2)$ & \\
\hline B3 & - & - & \\
\hline B4 & - & - & \\
\hline & Mean \pm S.D. & Mean \pm S.D. & \\
\hline $\mathrm{FSH}(\mathrm{mU} / \mathrm{ml})$ & $0.63(0.34)$ & $0.87(0.48)$ & $<0.001^{*}$ \\
\hline $\mathrm{LH}(\mathrm{mU} / \mathrm{ml})$ & $0.35(0.33)$ & $0.59(0.40)$ & $<0.001^{*}$ \\
\hline $\begin{array}{l}\text { Total testosterone } \\
\text { (ng/ml; No. } 25 \text { boys) }\end{array}$ & $0.25(0.16)$ & $0.58(0.43)$ & $<0.001^{\star}$ \\
\hline $\begin{array}{l}17 \beta \text {-Estradiol (pg/ml; } \\
\text { No. } 9 \text { girls) }\end{array}$ & $4.82(3.89)$ & $5.54(4.42)$ & $0.012^{*}$ \\
\hline
\end{tabular}

*Significant values when $P<0.05$ (Wilcoxon test). Normal values of FSH, $\mathrm{LH}$, total testosterone and 17ß-estradiol (prepubertal): $\mathrm{FSH}:<1.5 \mathrm{mU} / \mathrm{ml}$ $\mathrm{LH}<1.7 \mathrm{mU} / \mathrm{ml}$; total testosterone $<0.68 \mathrm{ng} / \mathrm{ml}$ (boys); $17 \beta$-estradiol $<10 \mathrm{pg} / \mathrm{ml}$ (girls). 

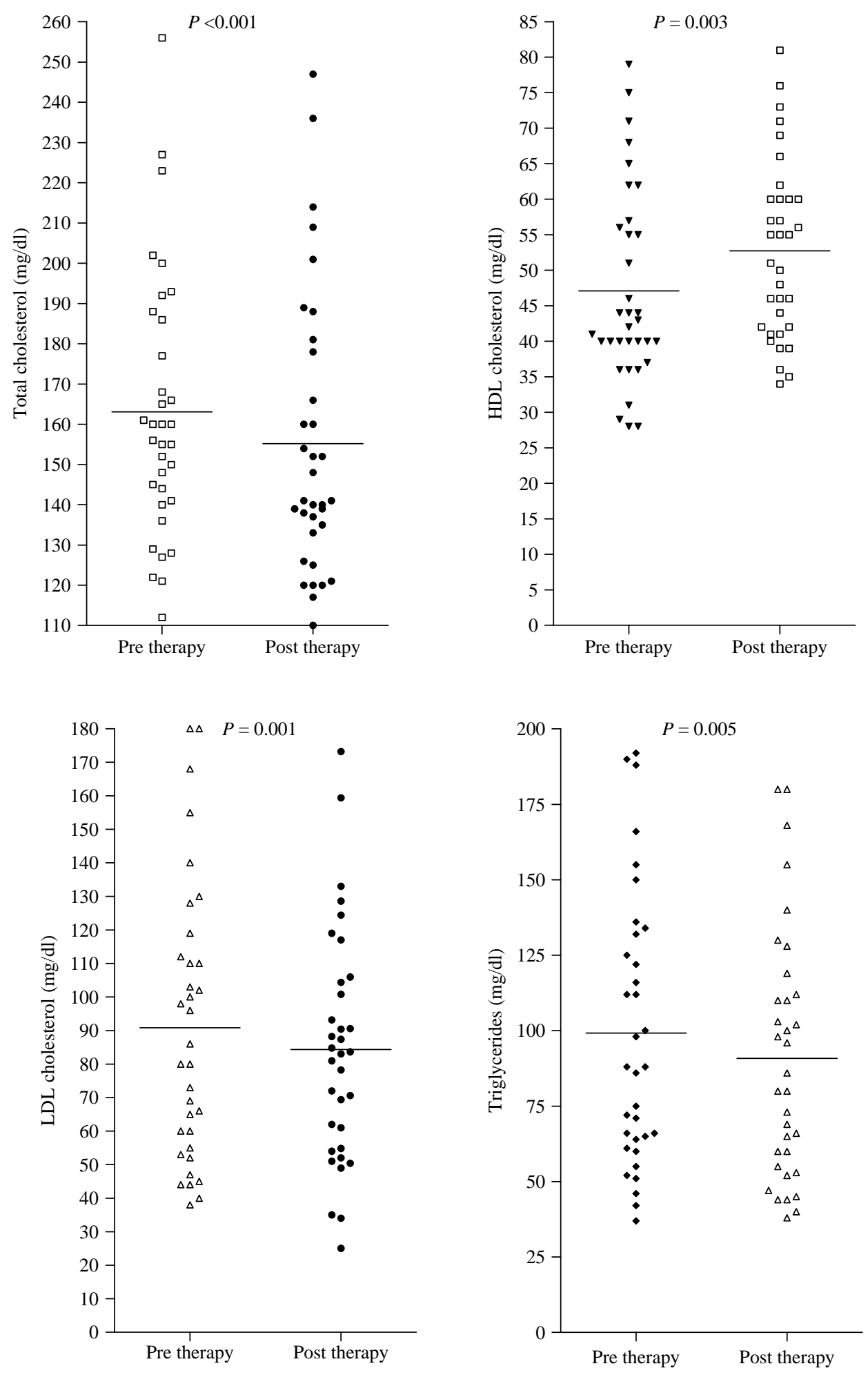

Significant values when $P<0.05$ (Wilcoxon test).

Figure 1 Lipid profile before and after 12 months of GH replacement therapy in GHD patients. 

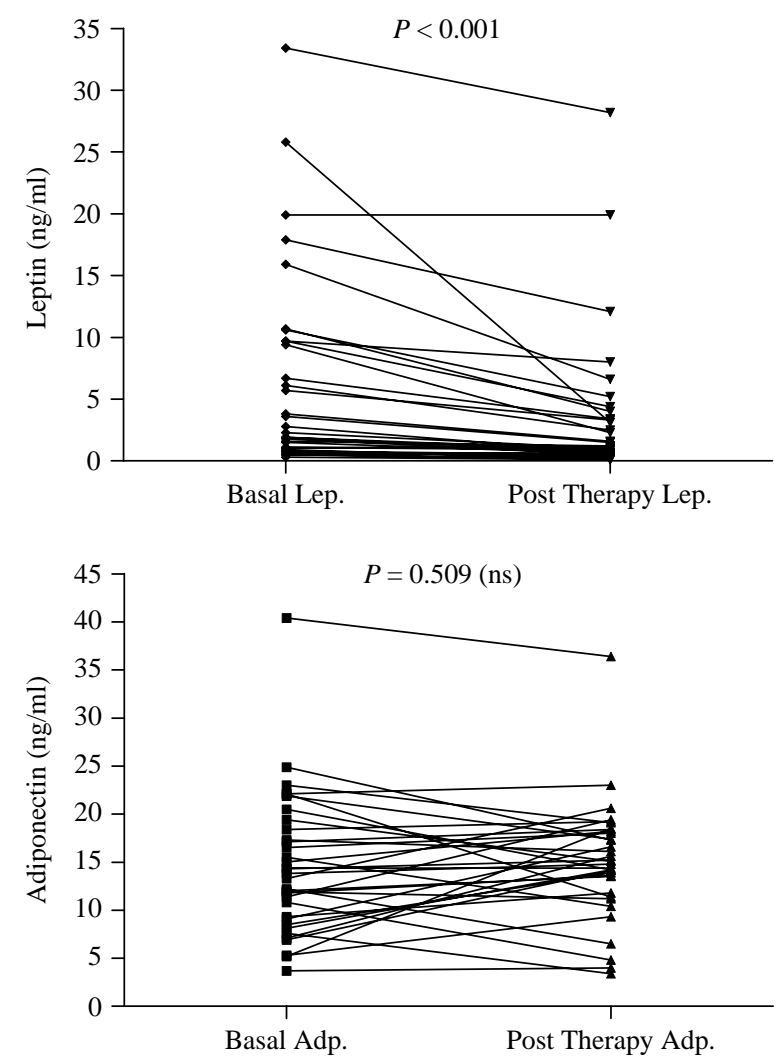

Significant values when $P<0.05$ (Wilcoxon test).

Figure 2 Leptin and adiponectin before and after 12 months of $\mathrm{GH}$ replacement therapy in GHD patients.

any change in glycemia. Lipids were highly influenced by $\mathrm{GH}$ therapy as in adults with GHD.

GH has both insulin-like (IGF-I dependent) and antiinsulin-like effects on cells and tissues. GH reduces body

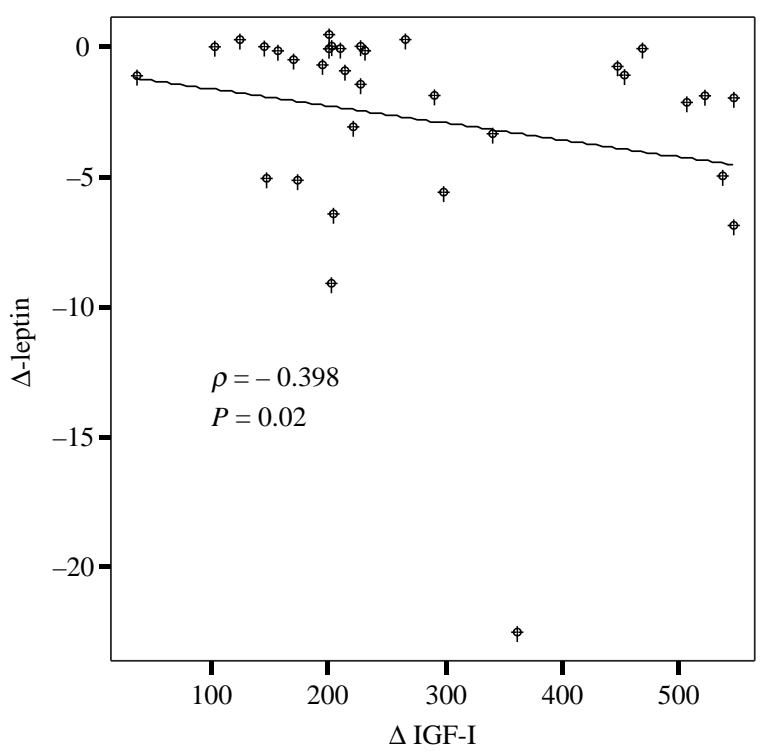

Significant values when $P<0.05$ (Spearman correlation).

Figure $3 \Delta \mathrm{IGF}-\mathrm{I} / \Delta$-leptin correlation. fat involving both decreased lipogenesis and increased lipolysis. For this reason, GHD in adult life is associated with alterations in body composition (increased central adiposity, deficit in lean mass, and osteopenia), decreased peripheral insulin sensitivity with modest fasting hyperinsulinemia, abnormal glucose tolerance, higher total and LDL cholesterol levels and a variable prevalence of hypertriglyceridemia, premature atherosclerosis and increased risk of cardiovascular disease (6). GH replacement therapy in adults has beneficial effects on all these parameters (18).

It is interesting to note that in GHD adolescents who discontinue $\mathrm{GH}$ treatment at completion of linear growth, there are unfavorable effects on body composition, glucose and lipid profiles, bone mineral density, and cardiac function (19-21). Lanes et al. (5) report increased LDL cholesterol levels in GHD adolescents when compared with healthy controls, whereas total HDL cholesterol and triglyceride concentrations were similar in the two groups; conversely, other authors have not reported any abnormalities in lipid profiles (22-24). In our study, at baseline, we found a significant difference in total and LDL cholesterol between GHD children and controls, with significantly higher levels in the first group, though still within the normal range. Kuromaru et al. reported a decrease in fat mass, LDL and total cholesterol, and an increase in lean mass and HDL cholesterol after 6 months of GH treatment (2). Our study also confirms improvement in lipid profile after 12 months of $\mathrm{GH}$ replacement therapy compared with baseline, with a significant reduction in total cholesterol, LDL, and triglyceride levels and a concomitant slight rise in HDL.

As several studies have reported, GH plays an important role in glucose and insulin metabolism. Some authors have found a degree of insulin resistance in untreated GHD adults and increased peripheral insulin sensitivity after $\mathrm{GH}$ therapy $(7,8)$; while others have not found any difference in glycemia, insulinemia, and HOMA-IR between untreated GHD adults and control subjects, or any variation after GH therapy (25). In pediatric patients, the effect of GH therapy on serum insulin levels has also been reported (26), showing a trend towards reduced insulin sensitivity with a compensatory hyperinsulinemic response. Saenger (27) reported a slight increase in insulin levels in a group of GHD children after 36 months of GH therapy, with normal glucose levels. Conversely, some authors have reported increased incidence of diabetes mellitus or impaired glucose tolerance in children and adolescents receiving $\mathrm{GH}$ treatment (28). In our study, we did not observe any significant difference between GHD patients and healthy subjects on baseline glycemic and insulinemic levels while after 12 months of GH replacement therapy we found an increase in insulin levels and HOMA-IR without any untoward effects on glucose metabolism. We hypothesize that the increase in HOMA-IR, due to the relative hyperinsulinemia, mainly 
brought about by the anti-insulin GH effects, probably does not reflect a real status of insulin-resistance, as suggested by the adiponectin levels. These levels, in fact, which are recognized as inversely related to insulin resistance (10), did not change during the first year of continuous therapy. In addition, the increase in insulin levels observed after $\mathrm{GH}$ treatment may be consistent with the absence of the inhibitory feedback of the leptin on insulin synthesis and release (adipoinsular axis) (29).

GH therapy has been shown to reduce serum leptin, but the complex interplay of the GH/IGF-I axis in the modulation of leptin levels is still not fully understood. Several studies have reported the effects of $\mathrm{GH}$ on adipokines in adult GHD (13). Matsuoka et al. (30) also observed changes in body composition and in leptin levels during the first year of GH therapy in short children without GHD. Our findings have shown that after 12 months of treatment, a significant decrease in leptin levels can be observed in GHD children; this effect may be related to body fat reduction, which is the predominant metabolic effect of therapy. Although it is by now generally accepted that during puberty both healthy and GHD females have higher leptin levels, we did not find any gender-related differences, probably because we enrolled only prepubertal subjects.

Moreover, the change in leptin levels observed during the 12 months of GH replacement therapy was inversely correlated with the change in IGF-I levels; in our study, therefore, leptin levels proved to be an adjunctive tool in metabolic evaluation during GH therapy (Fig. 3).

Table 4 Correlation between $\Delta \mathrm{TT} / \Delta \mathrm{E} 2$ and $\Delta$ metabolic data.

\begin{tabular}{llcc}
\hline $\boldsymbol{\rho}$ of Spearman & & $\boldsymbol{\Delta} \mathbf{T T}$ & $\boldsymbol{\Delta} \mathbf{E 2}$ \\
\hline$\Delta$ Total cholesterol & Correlation coefficient & -0.291 & 0.427 \\
& $P$ & 0.158 & 0.252 \\
& No cases & 25 & 9 \\
$\Delta$ HDL cholesterol & Correlation coefficient & 0.170 & 0.172 \\
& $P$ & 0.417 & 0.658 \\
& No cases & 25 & 9 \\
$\Delta$ LDL cholesterol & Correlation coefficient & -0.299 & 0.209 \\
& $P$ & 0.146 & 0.589 \\
$\Delta$ Triglycerides & No cases & 25 & 9 \\
& Correlation coefficient & -0.169 & -0.099 \\
& $P$ & 0.419 & 0.799 \\
$\Delta$ Insulin & No cases & 25 & 9 \\
& Correlation coefficient & 0.245 & -0.510 \\
$\Delta$ Homa-IR & $P$ & 0.239 & 0.160 \\
& No cases & 25 & 9 \\
& Correlation coefficient & 0.218 & -0.393 \\
$\Delta$ Leptin & $P$ & 0.294 & 0.295 \\
& No cases & 25 & 9 \\
$\Delta$ Adiponectin & Correlation coefficient & -0.169 & 0.510 \\
& $P$ & 0.419 & 0.160 \\
& No cases & 25 & 9 \\
& Correlation coefficient & 0.309 & -0.017 \\
& $P$ & 0.133 & 0.966 \\
& No cases & 25 & 9 \\
\hline
\end{tabular}

$\rho$ of Spearman correlation. Significant values when $P<0.05$.
In addition, in our prepubertal patients, the minimal physiological modifications in gonadotropin levels did not seem to influence the metabolic parameters examined, as demonstrated by the absence of a significant correlation between $\Delta$ in gonadotropin and sex hormones (total testosterone for boys and $17 \beta$-E2 for girls) and $\Delta$ in each metabolic parameter is examined (Table 4).

In conclusion, the results of this prospective study demonstrate that continuous $\mathrm{GH}$ replacement therapy in GHD children shows, at 12 months, an improvement in final height, restores IGF-I levels, reduces leptin levels and improves the lipid profile, without producing any unfavorable effects on glucose metabolism.

\section{References}

1 Blethen SL, Baptista J, Kuntze J, Foley T, La Franchi S \& Johanson A. Adult height in growth hormone (GH)-deficient children treated with biosynthetic GH. The Genentech Growth Study Group. Journal of Clinical Endocrinology and Metabolism 1997 $82418-420$.

2 Kuromaru R, Kohno H, Ueyama N, Hassan HM, Honda S \& Hara T. Long-term prospective study of body composition and lipid profiles during and after growth hormone (GH) treatment in children with GH deficiency: gender-specific metabolic effects. Journal of Clinical Endocrinology and Metabolism 199883 3890-3896.

3 Nørrelund H, Vahl N, Juul A, Møller N, Alberti KGMM, Skakkebaek NE, Sandhal Christiansen J \& Jørgensen JOL. Continuation of growth hormone (GH) therapy in $\mathrm{GH}$-deficient patients during transition from childhood to adulthood: impact on insulin sensitivity and substrate metabolism. Journal of Clinical Endocrinology and Metabolism 200085 1912-1917.

4 Vahl N, Juul A, Jørgensen JOL, Ørskov H, Skakkebaek NE \& Christiansen IS. Continuation of growth hormone (GH) replacement in GH-deficient patients during transition from childhood to adulthood: a two-year placebo-controlled study. Journal of Clinical Endocrinology and Metabolism 200085 1874-1881.

5 Lanes R, Gunczler P, Lopez E, Esaa S, Villaroel O \& Revel-Chion R. Cardiac mass and function, carotid artery intima-media thickness, and lipoprotein levels in growth hormone-deficient adolescents. Journal of Clinical Endocrinology and Metabolism $2001 \mathbf{8 6}$ 1061-1065.

6 Johannsson JO, Landin K, Tengborn L, Rosèn T \& Bengtsson BÅ. High fibrinogen and plasminogen activator inhibitor activity in growth hormone-deficient adults. Arteriosclerosis, Thrombosis, and Vascular Biology 199414 434-437.

7 Jorgensen JO, Pedersen SA, Thuesen L, Jorgensen J, IngermannHansen T, Skakkebaek NE \& Christiansen JS. Beneficial effect of growth hormone treatment in GH-deficient adults. Lancet 19891 1221-1225.

8 Salomon F, Cuneo RC, Hesp R \& Sönksen PH. The effects of treatment with recombinant human growth hormone on body composition and metabolism in adults with growth hormone deficiency. New England Journal of Medicine 1989321 1797-1803.

9 Considine RV \& Caro JF. Leptin: genes, concepts and clinical perspective. Hormone Research $199646249-256$.

10 Weyer C, Funahashi T, Tanaka S, Hotta K, Matsuzawa Y, Pratley RE \& Tataranni PA. Hypoadiponectinemia in obesity and type 2 diabetes: close association with insulin resistance and hyperinsulinemia. Journal of Clinical Endocrinology and Metabolism 200186 1930-1935.

11 Frederich RC, Hamann A, Anderson S, Lollmann B, Lowell BB \& Flier JS. Leptin levels reflect body lipid content in mice: evidence for diet-induced resistance to leptin action. Nature Medicine 19951 1311-1314. 
12 Eliman A, Norgren S \& Marcus C. Effects of growth hormone treatment on the leptin system and body composition in obese prepubertal boys. Acta Paediatrica 200190 520-525.

13 Engstrom BE, Burman P, Holdstock C \& Karlsson FA. Effect of growth hormone $(\mathrm{GH})$ on ghrelin, leptin and adiponectin in $\mathrm{GH}$ deficient patients. Journal of Clinical Endocrinology and Metabolism 200388 5193-5198.

14 Eliman A, Lindgren AC, Norgren S, Kamel A, Skwirut C, Bang P \& Marcus C. Growth hormone treatment downregulates serum leptin levels in children independent of changes in body mass index. Hormone Research 199952 66-72.

15 Growth Hormone Research Society. Consensus guidelines for the diagnosis and treatment of growth hormone $(\mathrm{GH})$ deficiency in childhood and adolescence: summary statement of the $\mathrm{GH}$ Research Society. Journal of Clinical Endocrinology and Metabolism 200085 3990-3993.

16 Matthews DR, Hosker JP, Rudenski AS, Naylor BA, Treacher DF \& Turner RC. Homeostasis model assessment: insulin resistance and beta-cell function from fasting plasma glucose and insulin concentrations in man. Diabetologia $1985 \mathbf{2 8} 412-419$.

17 Tanner JM, Whitehouse RH, Cameron N, Marshall WA, Healy MJR \& Goldstein H. Assessment of Skeletal Maturity and Prediction of Adult Height. 2nd edn. London: Academic Press, 1983.

18 Bengtsson BÅ, Edèn S, Lonn L, Kvist H, Stokland A, Lindstedt G, Bosaeus I, Tolli J, Sjostrom L \& Isaksson OG. Treatment of adults with growth hormone $(\mathrm{GH})$ deficiency with recombinant human GH. Journal of Clinical Endocrinology and Metabolism 199376 309-317.

19 Carroll PV, Drake WM, Maher KT, Metcalfe K, Shaw NJ, Dunger DB, Cheetam TD, Camacho-Hubner C, Savage MO \& Monson JP. Comparison of continuation or cessation of growth hormone $(\mathrm{GH})$ therapy on body composition and metabolic status in adolescents with severe GH deficiency at completion of linear growth. Journal of Clinical Endocrinology and Metabolism $2004893890-3895$.

20 Tauber M, Jouret B, Cartault A, Lounis N, Gayrard M, Marcouyeux C, Pienkowski C, Oliver I, Moulin P, Otal P, Joffre F, Arnaud C \& Rocchiccioli P. Adolescents with partial growth hormone $(\mathrm{GH})$ deficiency develop alterations of body composition after GH discontinuation and require follow-up. Journal of Clinical Endocrinology and Metabolism 200388 5101-5106.

21 Drake WM, Carroll PV, Maher KT, Metcalfe KA, CamachoHübner C, Shaw NJ, Dunger DB, Cheetham TD, Savage MO \& Monson JP. The effect of cessation of growth hormone $(\mathrm{GH})$ therapy on bone mineral accretion in $\mathrm{GH}$-deficient adolescents at the completion of linear growth. Journal of Clinical Endocrinology and Metabolism $2003 \mathbf{8 8} 1658-1663$.
22 Boot AM, Engels MAMJ, Boerma GJM, Krenning EP \& de Muinck Keizer-Schrama SMPF. Changes in bone mineral density, body composition and lipid metabolism during growth hormone $(\mathrm{GH})$ treatment in children with GH deficiency. Journal of Clinical Endocrinology and Metabolism 199782 2423-2428.

23 Lanes R, Paoli M, Carrillo E, Villaroel O \& Palacios A. Cardiovascular risk of young growth-hormone-deficient-adolescents. Differences in growth-hormone-treated and untreated patients. Hormone Research 200360 291-296.

24 Salerno M, Esposito V, Farina V, Radetti G, Umbaldo A, Capalbo D, Spinelli L, Muzzicca S, Lombardi G \& Colao A. Improvements of cardiac performance and cardiovascular risk factors in children with GH deficiency after two years of GH replacement therapy: an observational, open, prospective, case-control study. Journal of Clinical Endocrinology and Metabolism 200691 1288-1295.

25 Giavoli C, Porretti S, Ronchi CL, Cappiello V, Ferrante E, Orsi E, Arosio M \& Beck-Peccoz P. Long-term monitoring of insulin sensitivity in growth hormone-deficient adults on substitutive recombinant human growth hormone therapy. Metabolism 2004 53 740-743.

26 Heptulla RA, Boulware SD, Caprio S, Silver D, Sherwin RS \& Tamborlane WV. Decreased insulin sensitivity and compensatory hyperinsulinemia after hormone treatment in children with short stature. Journal of Clinical Endocrinology and Metabolism $1997 \mathbf{8 2}$ 3234-3238.

27 Saenger P. Metabolic consequences of growth hormone treatment in paediatric practice. Hormone Research 200053 60-69.

28 Cutfield WS, Wilton P, Bennmarker H, Albertsson-Wikland K, Chatelain P, Ranke MB \& Price DA. Incidence of diabetes mellitus and impaired glucose tolerance in children and adolescents receiving growth-hormone treatment. Lancet 2000 $355610-613$.

29 Seufert J. Leptin effects on pancreatic beta-cell gene expression and function. Diabetes 200453 152-158.

30 Matsuoka H, Fors H, Bosaeus I, Rosberg S, Albertsson-Wikland K \& Bjarnason R. Changes in body composition and leptin levels during growth hormone $(\mathrm{GH})$ treatment in short children with various GH secretory capacities. European Journal of Endocrinology $199914035-42$.

Received 20 June 2006

Accepted 6 December 2006 